\title{
An Empirical Analysis of Consumers' Continuance Intention Towards Online Shopping
}

\author{
Imdadullah Hidayat-ur-Rehman ${ }^{1}$
}

Dr. Shamsul Anuar Mokhtar2

\author{
Dr. Hamidon Katan ${ }^{3}$ \\ ${ }^{1}$ MIS Department, College of Business Administration, King Saud University, Riyadh Saudi Arabia, UniKL MIIT \\ Universiti of Kuala Lumpur, Malaysia; ihidayaturrehman@ksu.edu.sa, imdadullah.hidayat@s.unikl.edu.my \\ 2 UniKL MIIT, Universiti of Kuala Lumpur, Malaysia; shamsulamuar@unikl.edu.my \\ 3 UniKL MIIT, Universiti of Kuala Lumpur, Malaysia; hamidon@unikl.edu.my
}

\section{Doi:10.5901/mjss.2016.v7n5p95}

\section{Abstract}

\begin{abstract}
Electronic commerce has provided opportunities to businesses to enhance their sale at the door steps of consumers. Consumers' repurchase intention becomes a challenge to businesses most of the times. This study develops a research model based on Technology Acceptance Model (TAM), Task technology Fit (TTF), Perceived Trust, Perceived Enjoyment and Expectation Confirmation Model (ECM) to study the factors affecting online shopping continuance. Sample data was collected from Saudi Arabia by conducted a survey. Empirical data from 218 consumers was tested against the proposed model by using Structural Equation Modeling (SEM). The results reveal that perceived trust, perceived usefulness and online shopping satisfaction have significant effects on online shopping continuance. Predictors for perceived trust are perceived enjoyment and task technology fit. Perceived ease of use, confirmation and task technology fit are predictors of perceived usefulness. Effects of confirmation and Task technology fit are significant on online shopping satisfaction. The direct effect of perceived enjoyment on online shopping continuance is not significant. Recommendations based on the implications of the findings have been concluded in this paper.
\end{abstract}

Keywords: E-Commerce, Online Shopping, Information Systems (IS), Technology Acceptance Model

\section{Introduction}

Electronic commerce (e-commerce) is a type of business model that enables a firm or individual to conduct business over an electronic network, typically the internet. It enables people to meet many of their business needs simply by using a keyboard and mouse. The number of internet users are increasing at a very high speed. According to Internet World Stats, 2015, there are more than 3 billion internet users all over the world and more than 18 Million people have access to the internet in Saudi Arabia ("Internet World Stats," 2015).

E-commerce is becoming popular among Saudi Arabian users but still the number of users making online shopping is very low. According to CITC survey report 2014, only $10.41 \%$ online shopping e-service is used in Saudi Arabia and $8.54 \%$ e-payment service is used for receiving orders. According to a study made by (Alshehri \& Drew, 2012), among 350 online consumers in Saudi Arabia 45\% were not interested in e-procurement. Despite its fast growing economy and the rapid increasing internet usage, E-commerce growth is slower in Saudi Arabia (Makki \& Chang, 2015).

Despite heavy investments on IS for online shopping, retaining existing customers becomes a challenge to the businesses. According to, Bhattacherjee (2001a), success of an IS depend on its continuous use rather than first time use. Thus continuation intention has become more important in the study of e-commerce.

The main purpose of this study is to enhance our understating of the formation of consumers' continuance intention towards online shopping and identify ways through which the businesses retain the existing users. Technology Acceptance Model (TAM) and Expectation Confirmation Model (ECM) cover continuance intention from users' perceptions towards technology. Continuance intention cannot be determined only from users' perceptions but technology fit of task plays an important role in continuance intention. Other than technology features, consumers' trust is also important for continuation of the service. The extant research is mainly focused on adoption of online shopping and repurchase intention has rarely been addressed. To fill this gap, this study is based on a holistic model combining TAM, ECM, TTF, Perceived Enjoyment and perceived Trust to provide an empirical evidence of the factors affecting consumers' continuance intention towards online shopping. 


\section{Literature Review}

To enhance consumers' online shopping behavior, it is crucial for businesses to have a better understanding of not only consumers' perceptions about the technology but technology factors that best fit the tasks of online shopping. Other than these two important antecedents, Trust plays important role in continuation of intention (Baptista \& Oliveira, 2015). With the changes in the technology feature of IS in terms of website features and functionalities, interface design and internet security, users' perceptions are also changing and the online channel is becoming more popular. Therefore, research is needed on consumers' continuation intention.

Davis proposed a model (TAM) based on Theory of Reasoned Action to understand users' acceptance of information systems (Davis, 1989). According to TAM, perceived usefulness and perceived ease of use are the important antecedents to determine users' intention to use IS which in turn determines the actual system use (Davis, 1989). Within IS theories, TAM has been confirmed as the most parsimonious framework and it has been widely used and integrated with other factors to create new frameworks (Wen, Prybutok, \& Xu, 2011). (Moon \& Kim, 2001; Shin, 2007) used TAM in their studies to explain the users' intention to adopt IS. TAM was also implemented in several researches to understand the users' continuation intention to use IS (Gefen, Karahanna, \& Straub, 2003; Hung, Chang, \& Kuo, 2013; S. S. Kim \& Malhotra, 2005).

ECM has been devised by (Bhattacherjee, 2001) by extending expectation confirmation theory. ECM describe the users' continuation intention and focuses on post-acceptance constructs. The pre-acceptance constructs are covered by satisfaction and confirmation while perceived usefulness is representing the expectations. According to ECM, a user forms an opinion about the system after first time use and perceives about system usefulness. With the passage of time, the perceived usefulness and confirmation leads the user to satisfaction about the system. The user's satisfaction and user's perceived usefulness lead the user to make an intention to continue the system (Bhattacherjee, 2001). ECM can help in understanding users' behaviours which is difficult to understand by initial adoption theories (Yuan, Liu, Yao, \& Liu, 2014).

Many researchers (M. C. Lee, 2010; Y. Lee \& Kwon, 2011; Thong, Hong, \& Tam, 2006) have used ECM to understand users' continued usage of IS and have confirmed that that ECM is an effective model to predict continuance intention in the context of online shopping. Therefore, the current study is using ECM to understand the consumers' continuance intention towards online shopping.

Trust and Enjoyment, social/psychological factors, are also important in continuing intention to shop online. The businesses are spending more for creation of mutual trust that can give confidence to customers with online transactions through which the products become attractive to customers (Aren, Güzel, Kabadayı, \& Alpkan, 2013; Gefen et al., 2003; Hassanein \& Head, 2007). Enjoyment is also an important factor for continuation intention of using a technology. When a person engages him in an activity and he feels pleasure after performing action, this feeling of pleasure is called enjoyment (Moon \& Kim, 2001). The online shopping activity should bring an intrinsic motivation that promotes the user's intention for continuation after adoption. This study will test the influence of trust and enjoyment on consumers' continuance intention towards online shopping.

According to TTF model, the user adopts a new technology if it is executing the daily task efficiently. Hence, the adoption to a new IS will depend greatly on the users' daily tasks. The model explains that mere users' perceptions of the technology are not enough to predict acceptance (Goodhue \& Thompson, 1995). TTF is dependent on two factors task characteristics and technology characteristics that leads to the adoption and use of a specific technology. TTF has been used in several studies to understand the users' behaviours about technology acceptance, pre-adoption and post adoption continuation (Afshan \& Sharif, 2016b; Oliveira, Faria, Thomas, \& Popovi??, 2014; Wen et al., 2011; Yuan et al., 2014; Zhou, Lu, \& Wang, 2010). According to the previous studies, TTF shows good combination with TAM and ECM in understanding continuation intention to shop online. The current study is identifying the influence of TTF on trust, perceived usefulness and satisfaction in the context of online shopping.

\section{Conceptual Framework and Hypotheses}

\subsection{Technology Acceptance Model (TAM) \& Expectation Confirmation Model (ECM)}

In our model, the utilitarian factors perceived ease of use (PEU), perceived usefulness (PU), satisfaction and confirmation have been taken from TAM and ECM. PEU is defined as "the degree to which a person believes that using a particular system would be free of effort" (Davis, 1989). According to TAM, PEU has influence on PU which in turn affects the intention. Empirical evidences from the literature show the indirect significant effect of PEU on intention mediated by PU 
(Hong, Thong, \& Tam, 2006; G. Kim, Shin, \& Lee, 2009). In the context of online shopping, if the user will find a user friendly interface, good website features to search required items and easy to transact will lead him to make continuation intention.

Davis defined PU as "the degree to which a person believes that using a particular system would enhance his or her job performance". If an online channel will be easy to use, it will have positive effects on usefulness and in turn user's satisfaction over the channel will be increased. ECM posits that PU has positive effect on satisfaction and confirmation of expectations has positive impact on PU. If user's perception regrading usefulness is not concrete, it can be adjusted by confirmation experience and fulfillment expectations from IS (M. C. Lee, 2010). Thus, the following hypotheses are proposed:

H1. PEU is positively related to PU.

$\mathrm{H} 2$. PU is positively related to Online Shopping Continuance (OSC).

H3. Confirmation is positively related to PU.

$\mathrm{H} 4$. Confirmation is positively related to Online Shopping Satisfaction (OSS).

$\mathrm{H} 5$. PU is positively related to OSS

H6. OSS is positively related to OSC.

\subsection{Perceived Trust (PT)}

The willingness of a person to take risks in order to fulfill a need without prior experience, or credible, meaningful information is termed as Initial trust (K. K. Kim \& Prabhakar, 2004). The role of trust becomes more important in the context of e-commerce due to many uncertainties of distance and non-visibility of the original business (Wen et al., 2011). Violation of trust in e-commerce will result in negative intention towards repurchase (Goles, Lee, Rao, \& Warren, 2009). In case of e-commerce, the customers have to rely on trust due to the lack of regulations (Gefen \& Straub, 2004). In a study made by (Gefen \& Straub, 2004), trust influenced usage intention directly and indirectly via perceived usefulness. Moreover, if an online channel will be more easy to use, it will add more confidence and trust to the user. Thus, the following hypotheses are proposed:

H7. PEU is positively related to PT.

H8. PT is positively related to PU.

H9. PT is positively related to OSC.

\subsection{Task Technology Fit (TTF)}

According to TTF, the user adopts a new technology if it is executing the daily tasks efficiently. The model explains that mere users' perception of the technology is not enough to predict acceptance (Goodhue \& Thompson, 1995). TTF has been used in several studies. An integrated TTF model with TAM was used to explain the relationship between software use and user performance by (Dishaw \& Strong, 1999; K. S. Lee, Lee, \& Kim, 2007) used a modified TTF model to explore the factors affecting the adoption of m-Commerce in the insurance industry. To study e-commerce adoption, (Klopping \& McKinney, 2004) used a model combining TTF and TAM. A study made by (Malaquias \& Hwang, 2016) has confirmed the positive relationship of task characteristics and trust. These studies confirmed that TTF is important in identifying user's behaviour of technology adoption and continuation. Thus, the following hypotheses are proposed:

H10. TTF is positively related to PT.

H11. TTF is positively related to PU.

H12. TTF is positively related to OSS.

\subsection{Perceived Enjoyment (PE)}

Perceived enjoyment was defined by (Venkatesh \& Davis, 2000) as "The extent to which the activity of using a specific system is perceived to be enjoyable in its own right, aside from any performance consequences resulting from system use". Customers use to go to physical stores because they feel shopping enjoyable. Enjoyment in online shopping is as necessary as in physical shopping environment and it has important influence on customer intention. Intrinsic and extrinsic motivations lead the customers towards online shopping: (Aren et al., 2013). Extrinsic motivation is a reaction to things independent from situation (PU, PEU, subjective norms etc.). Intrinsic motivations drive actions demonstrated for the action itself e.g., an interesting and satisfying act refers to intrinsic motivation (M. J. Kim, Chung, \& Lee, 2011). In prepurchase phase, factors like PEU and PT are important to attract the customer but in-post purchase phase the sense of 
enjoyment will influence continuation intention of the customer. Thus, the following hypotheses are proposed:

$\mathrm{H} 13$. PE is positively related to PT.

H14. PE is positively related to OSC.

\section{Conceptual Model}

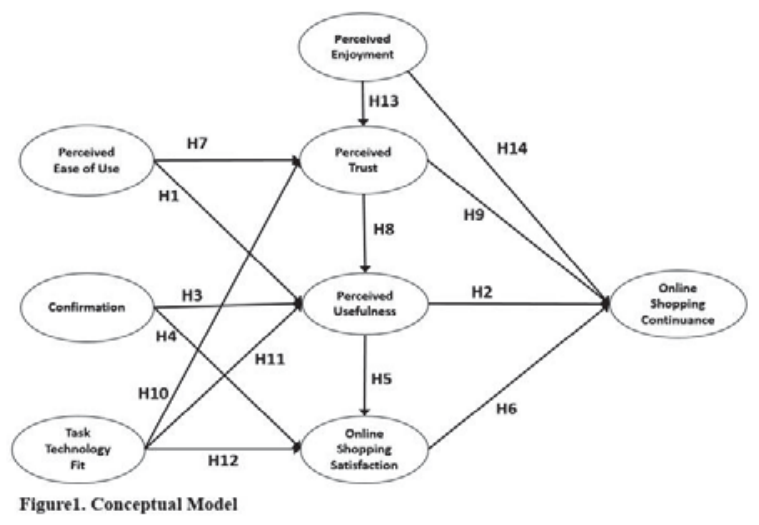

\section{Methodology}

\subsection{Research Instrument Development}

A questionnaire was prepared to collect data and to test and validate our theoretical model. The questionnaire is composed of two parts. The first part contains questions about demographics. The second part contains 30 questions measuring the 8 constructs of the model. A five-point Likert Scale is used to measure the items in questionnaire. All items in the instrument have been adopted from previous relevant research and have been modified accordingly. Some sample questions from the questionnaire are given below.

\begin{tabular}{|l|l|l|l|l|l|}
\hline Perceived Ease of Use & Strongly Disagree1 & Disagree 2 & Neutral 3 & Agree 4 & Strongly Agree 5 \\
\hline Factors & & & & & \\
\hline The online shopping website is easy to use & & & & \\
\hline The online shopping website is flexible to interact with & & & & \\
\hline It is easier to use the Internet to find products that I want to buy & & & \\
\hline
\end{tabular}

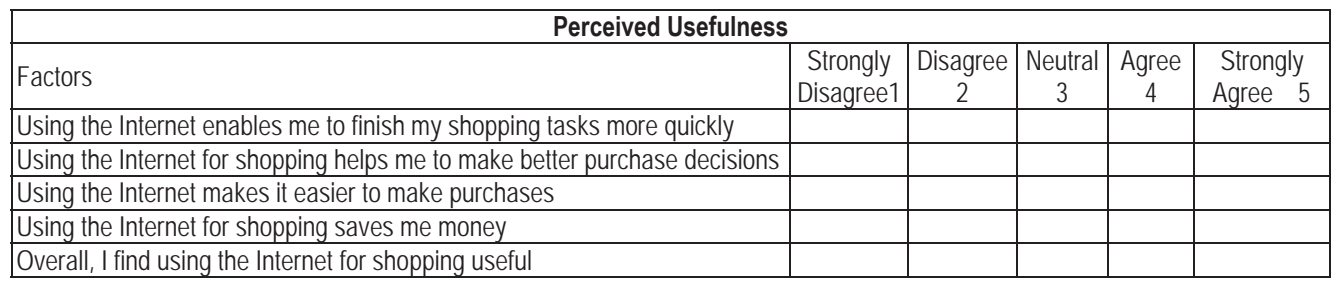

\subsection{Data Collection and Sample}

We employed a survey to address our research objectives. We have used Structural Equation Modeling to test our hypotheses which needs at least 200 sample size (Hoelter, 1983). The questionnaire was sent online to 1000 participants including faculty, staff, students of university and employees of business organizations out of which 319 (31.9\%) online responses were received. The received responses were analyzed for missing data or non-pertinent responses. Based on initial analysis, 101 cases were discarded and remaining 218 were used for model testing. Demographics details have been depicted in Table-1. 


\begin{tabular}{|c|c|c|}
\hline Item & Characteristics & Percentage (\%) \\
\hline \multirow{2}{*}{ Gender } & Male & 78.9 \\
\hline & Female & 21.1 \\
\hline \multirow{5}{*}{ Age Group } & Below 20 years & 21.6 \\
\hline & 21 to 30 years & 41.3 \\
\hline & 31 to 40 years & 17.9 \\
\hline & 41 to 50 years & 11.5 \\
\hline & Over 50 years & 7.8 \\
\hline \multirow{4}{*}{ Qualification } & High School & 11.5 \\
\hline & Undergraduate & 45.0 \\
\hline & Graduate & 27.1 \\
\hline & Other & 16.5 \\
\hline \multirow{6}{*}{ Employment } & Full Time & 42.7 \\
\hline & Part Time & 5.5 \\
\hline & Self Employed & 1.4 \\
\hline & Student & 50.0 \\
\hline & Retired & 0.5 \\
\hline & Other & 0.0 \\
\hline \multirow{6}{*}{ Nationality } & Saudi & 62.3 \\
\hline & Egyptian & 1.9 \\
\hline & Pakistani & 23.7 \\
\hline & Pilipino & 0.5 \\
\hline & Indian & 4.7 \\
\hline & Other & 7.0 \\
\hline \multirow{2}{*}{ Online purchased made? } & Yes & 72.9 \\
\hline & No & 27.1 \\
\hline \multirow{2}{*}{ Type of purchase like? } & Online Shopping & 43.1 \\
\hline & Make shopping at physical stores & 36.9 \\
\hline
\end{tabular}

\section{Results}

As recommended by (Anderson \& Gerbing, 1988), we followed two-step i.e. we conducted Confirmatory Factor Analysis (CFA) to test the measurement model and then an assessment of the structural model was made. Maximum likelihood approach was used as an estimation method.

\subsection{Confirmatory Factor Analysis (CFA)}

We used AMOS 21 to conduct CFA to test our measurement model. The psychometric properties of scale were tested in terms of reliability and convergent/discriminant validity. To test the reliability, (Cronbach alpha>0.7) and composite reliability (rho>0.7) have been used. Values given in Table-2 show that both of the values meet the minimum criteria.

To test the convergent and discriminant validity of the scale, (Fornell \& Larcker, 1981) criterion was used. According to this criterion, if the average variance extracted (AVE) for each construct is greater than 0.5 , then convergent validity is established. If the AVE of each construct is greater than the shared variance, discriminant validity is established. Square roots of the AVE values and correlations among the constructs are given in Table-3. The square roots of the AVE values (The diagonal elements) are greater than the correlations among the constructs (off-diagonal elements). It represents good discriminant validity.

To check whether the actual observed data can be explained by the measurement model, the model was assessed in terms of different indices (the ratio between Chi-square and degrees of freedom ( $\left.X^{2} / \mathrm{df}\right)$ : standard root means square residual (SRMR): root mean square error of approximation (RMSEA): goodness of fit index (GFI): adjusted goodness of fit index (AGFI): normed fit index (NFI): comparative fit index (CFI): and Tucker-Lewis index (TLI)). All model fit indices $\left(\chi^{2}\right.$ Idf : 1.261; RMSEA: .035; GFI: .905; AGFI: .873 ; NFI: .891; CFI: .975; TLI: .969) are within in the recommended level as shown in Table-4. 


\subsection{Structural Model}

Table-4 shows that the structural model goodness-of-fit indices (X2/df : 1.288; RMSEA: .036; GFI: .900; AGFI: 871 ; NFI: .884; CFI: .971; TLI: .966) are comparable with the measurement model. An evidence of fitness between the hypothesized model and the observed data is given by the model fit indices.

Figure-2 shows the path analysis of structural equation modeling and a summary of hypothesis testing has been given in Table-5. The results indicate that OSC is jointly predicted by PT, PU and OSS supporting H9, H2 and H6. PT is predicted by TTF and PE supporting H10 and H13. PEU, Confirmation, PT and TTF have significant effects on PU. Thus $\mathrm{H} 1, \mathrm{H} 3, \mathrm{H} 8$ and $\mathrm{H} 11$ are supported. OSS is predicted by Confirmation, PU and TTF thus supporting H4, H5 and H12. The effects of PEU on PT are not significant which means that consumer's trust on the online channel is independent of easiness of use. Our hypotheses $\mathrm{H} 14$ was not supported which means that for OSC, enjoyment does not lead directly to repurchase intention but in turn increases the consumer's trust in the channel which leads to continuation of the online shopping channel.

\begin{tabular}{|c|c|c|c|c|c|c|c|}
\hline Constructs & Items & Means & \begin{tabular}{|c|} 
Standard \\
Deviations
\end{tabular} & \begin{tabular}{|c|} 
Factor \\
Loading
\end{tabular} & $\begin{array}{c}\text { Cronbach's } \\
\text { Alpha }\end{array}$ & CR & AVE \\
\hline \multirow{3}{*}{$\begin{array}{l}\text { Perceived Ease } \\
\text { of Use }\end{array}$} & PEU1 & 3.98 & 530 & 613 & \multirow{3}{*}{.740} & \multirow{3}{*}{0.724} & \multirow{3}{*}{0.574} \\
\hline & PEU2 & 4.11 & .656 & .767 & & & \\
\hline & PEU3 & 4.23 & .702 & .718 & & & \\
\hline \multirow{5}{*}{$\begin{array}{l}\text { Perceived } \\
\text { Usefuluess }\end{array}$} & PU1 & 3.83 & .798 & 865 & \multirow{5}{*}{.883} & \multirow{5}{*}{0.884} & \multirow{5}{*}{0.603} \\
\hline & PU2 & 3.76 & .780 & 690 & & & \\
\hline & PU3 & 3.78 & .796 & .768 & & & \\
\hline & PU4 & 3.74 & .864 & 688 & & & \\
\hline & PU5 & 3.84 & 841 & .784 & & & \\
\hline \multirow{3}{*}{ Confirmation } & CONF1 & 3.84 & .776 & .762 & \multirow{3}{*}{.762} & \multirow{3}{*}{0.764} & \multirow{3}{*}{0.521} \\
\hline & CONF2 & 3.82 & .699 & .660 & & & \\
\hline & CONF3 & 3.95 & .739 & .740 & & & \\
\hline \multirow{4}{*}{$\begin{array}{l}\text { Online Shopping } \\
\text { Satisfaction }\end{array}$} & oss1 & 3.59 & 897 & 671 & \multirow{4}{*}{.809} & \multirow{4}{*}{0.758} & \multirow{4}{*}{0.513} \\
\hline & OSS2 & 3.61 & 819 & 668 & & & \\
\hline & OSS3 & 3.59 & 817 & 693 & & & \\
\hline & \begin{tabular}{|l|} 
OSS4 \\
\end{tabular} & 3.48 & 912 & .802 & & & \\
\hline \multirow{5}{*}{ Perceived Trust } & PT1 & 3.50 & .849 & 848 & \multirow{5}{*}{911} & \multirow{5}{*}{0.899} & \multirow{5}{*}{0.690} \\
\hline & PT2 & 3.52 & 816 & 900 & & & \\
\hline & PT3 & 3.83 & .866 & .660 & & & \\
\hline & PT4 & 3.69 & .800 & .735 & & & \\
\hline & PT5 & 3.62 & .857 & 830 & & & \\
\hline \multirow[t]{2}{*}{ Task } & TIF1 & 3.57 & 824 & 852 & \multirow{3}{*}{.790} & \multirow{3}{*}{0.773} & \multirow{3}{*}{0.631} \\
\hline & TIF2 & 3.57 & .748 & 815 & & & \\
\hline Technology Fit & TTF3 & 3.54 & 848 & 527 & & & \\
\hline \multirow{4}{*}{$\begin{array}{l}\text { Perceived } \\
\text { Enjoyment }\end{array}$} & PE1 & 3.67 & .870 & 545 & \multirow{4}{*}{.796} & \multirow{4}{*}{0.765} & \multirow{4}{*}{0.520} \\
\hline & PE2 & 3.61 & .797 & 646 & & & \\
\hline & PE3 & 3.54 & 821 & 682 & & & \\
\hline & PE4 & 3.55 & .859 & 804 & & & \\
\hline \multirow{3}{*}{$\begin{array}{l}\text { Online Shopping } \\
\text { Continuance }\end{array}$} & $\mathrm{OSCl}$ & 3.61 & .852 & .752 & \multirow{3}{*}{.791} & & \\
\hline & \begin{tabular}{|l|}
$\mathrm{OSC} 2$ \\
\end{tabular} & 3.57 & .857 & 506 & & 0.768 & 0.623 \\
\hline & \begin{tabular}{|l|}
$\mathrm{OSC} 3$ \\
\end{tabular} & 3.74 & 921 & 667 & & & \\
\hline
\end{tabular}

Table 3. Discriminant Validity

\begin{tabular}{|l|r|r|r|r|r|r|r|r|}
\hline & \multicolumn{1}{|c|}{ TIF } & PT & PU & PE & OSS & CONF & PEU & \multicolumn{1}{l|}{ OSC } \\
\hline TTF & 0.794 & & & & & & & \\
\hline PT & 0.513 & 0.831 & & & & & & \\
\hline PU & 0.529 & 0.569 & 0.77 & & & & & \\
\hline PE & 0.538 & 0.450 & 0.488 & 0.721 & & & & \\
\hline OSS & 0.477 & 0.517 & 0.623 & 0.404 & 0.716 & & & \\
\hline CONF & 0.282 & 0.292 & 0.458 & 0.331 & 0.477 & 0.722 & & \\
\hline PEU & -0.187 & 0.056 & 0.144 & 0.103 & 0.042 & 0.058 & 0.757 & \\
\hline OSC & 0.485 & 0.583 & 0.685 & 0.456 & 0.583 & 0.532 & 0.141 & 0.789 \\
\hline
\end{tabular}

Table 4. Fit Indices for Measurement and Structural Models

\begin{tabular}{|c|r|r|r|}
\hline Fit Indices & Recommended Value & Measurement Model & Structural Model \\
\hline$\chi^{2}$ & & 282.363 & 298.755 \\
\hline df & & 224 & 232 \\
\hline$\chi^{2} /$ df & $<3$ & 1.261 & 1.288 \\
\hline RMSEA & $<0.08$ & 0.035 & 0.036 \\
\hline GFI & $>0.9$ & 0.905 & 0.9 \\
\hline AGFI & $>0.9$ & 0.873 & 0.871 \\
\hline NFI & $>0.9$ & 0.891 & 0.884 \\
\hline CFI & $>0.9$ & 0.975 & 0.971 \\
\hline TLI & $>0.9$ & 0.969 & 0.966 \\
\hline
\end{tabular}




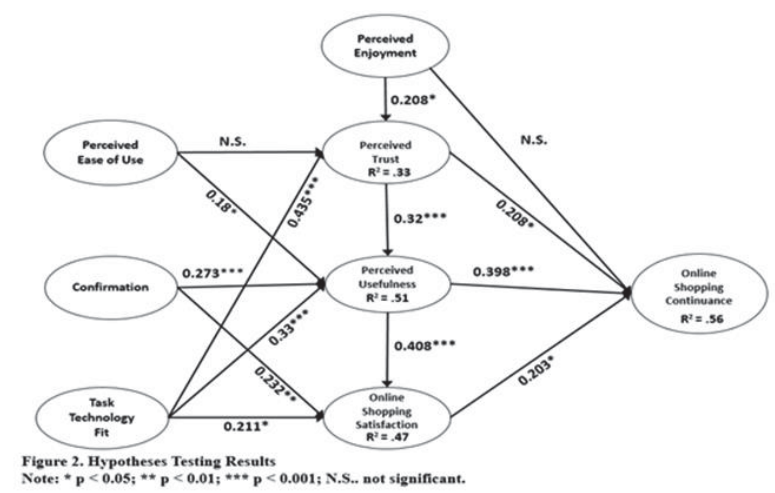

Table 5. Summary of Hypotheses Testing

\begin{tabular}{|c|c|c|c|c|}
\hline Hypotheses & $\begin{array}{c}\text { Standardised } \\
\text { Path } \\
\text { Coefficients }\end{array}$ & T-Value & P-Value & $\begin{array}{c}\text { Hypotheses } \\
\text { Testing }\end{array}$ \\
\hline HI. PEU $\ldots>$ PU & 0.18 & 2.219 & $0.026^{*}$ & Supported \\
\hline H2. PU $\ldots>$ OSC & 0.398 & 3.703 & $\cdots$ & Supported \\
\hline H3. CONF .... PU & 0.273 & 3.721 & $\cdots$ & Supported \\
\hline H4. CONF $\ldots$ OSS & 0.232 & 2.669 & $0.008 \cdots$ & Supported \\
\hline H5. PU $\ldots$ OSS & 0.408 & 4.07 & $\cdots$ & Supported \\
\hline H6. OSS $\cdots$ OSC & 0.203 & 2.042 & $0.041^{*}$ & Supported \\
\hline H7, PEU $\ldots$ PT & 0.119 & 1.438 & 0.151 & Not Supported \\
\hline H8. PT $\ldots>$ PU & 0.320 & 3.993 & $\cdots$ & Supported \\
\hline H9. PT $\cdots$ OSC & 0.208 & 2.432 & $0.015^{*}$ & Supported \\
\hline H10. TTF $\ldots$ PT & 0.435 & 4.071 & $\cdots$ & Supported \\
\hline H11. TIF $\ldots$ PU & 0.330 & 3.576 & $\cdots$ & Supported \\
\hline H12. TIF $\ldots$ OSS & 0.211 & 2.282 & $0.022^{\circ}$ & Supported \\
\hline H13. PE $\ldots$ PT & 0.208 & 2.046 & $0.041^{*}$ & Supported \\
\hline H14. $\mathrm{PE} \cdots$ OSC & 0.108 & 1.274 & 0.203 & Not Supported \\
\hline
\end{tabular}

\section{Discussion}

The current study focuses on the antecedents of consumers' continuance intention towards online shopping. The results confirm that only users' perceptions are not enough for a better online shopping service. Other important factors like technology fitness to the task, satisfaction, confirmation of user's expectations, usefulness and trust play important role in continuation of online shopping.

Significant effects of confirmation on usefulness and satisfaction have been validated. It was confirmed by previous researches also (Bhattacherjee, 2001; Wen et al., 2011). Our results show that satisfaction is an important factor of consumer's online shopping continuance which is consistent with the previous studies on satisfaction-intention in IS research (Bhattacherjee, 2001; Wen et al., 2011; Zhou, 2012). Hence, the businesses should focus more on fulfilment of expectations. Moreover, the results of this study indicate the significant effects of PU on OSS and OSC which confirms the results of previous researches. If the consumers will find an online shopping website useful, they will feel more satisfied and will intend to repurchase. Therefore, the businesses should keep their e-commerce websites easy to use and useful to confirm their expectations and to make them satisfied with the selected service.

According to our results, TTF has significant effects on PT, PU and OSS. It shows that an arrangement merely based on consumers' perceptions will not be enough for re-purchase intention. The businesses should ensure technology fitness to the online shopping tasks to meet users' satisfaction level and to gain their trust. Our findings regarding TTF have confirmed results of previous researches (Afshan \& Sharif, 2016a; Malaquias \& Hwang, 2016).

The relationship of PT with PU and OSC is also significant. In case of online shopping, the consumers are always concerned about the risks, security of payments and privacy of their information. Therefore, it is recommended that businesses should ensure trustworthiness of their online shopping IS. In contrast to previous research (Wen et al., 2011), our study shows that PE has no direct significant effect on OSC and rather it has an indirect significant effect on PT. It shows that the enjoyment felt by the user increases user's trust in the system that in turn leads to repurchase intention. 


\section{Theoretical \& Practical Implications}

This research has attempted to identify the factors affecting consumers' online shopping continuance and thus contributes to literature. The extant research on online shopping continuance focused on technology perceptions and rarely focused on TTF and trust along with technology perceptions in the context of online shopping. Our results confirm the significant effects of TTF on important antecedents of OSC i.e., PT, PU and OSS. Another important finding is the indirect effect of PE on OSC which needs to be validated in further research. The integrated model of this study provides a good explanatory power of continued usage intention. Future research may study continuance intention of other online services based on our model.

This study has useful implications to practice also. Our results help the e-commerce companies to understand important factors that influence the online shopping continuance. This understanding will help them to improve their strategies to retain their customers. According to our results, the strongest predictor of OSC is PU which in turn is predicted by PEU, confirmation and TTF. The businesses should focus on making the online shopping more useful by keeping it user friendly and easy to use which can meet consumers' expectations. They should also guarantee technology fitness according to the tasks carried out. The significant effects of Trust on usefulness suggest that the businesses should make every effort to make their online service trustworthy.

\section{Limitations and Future Research}

This research contributes to literature by incorporating TAM, TTF and ECM with trust and enjoyment to predict online shopping continuance. Validity of the measurement model and goodness-of-fit of structural model have been confirmed. However, there are certain limitations that need further exploration.

The model in this research accounts for 56 percent of the variance in online shopping continuance which indicates that there are some other factors which needs consideration. Future research may identify other factors influencing online shopping continuance.

Demographics details of our sample indicate that $45 \%$ in our sample are undergraduate and $43.6 \%$ graduate or Ph.D. The education level may affect users' perceptions and trust. People with less education may have different perceptions regarding a specific technology. Further studies may explore the effects of different educational levels on continuation intention. Moderating effects of age, gender and experience were not taken into account in this study. Future research may address this limitation.

The study was conducted by collecting data at one time. Behaviours of consumers are dynamic. Researchers may carry out longitudinal study to compare and evaluate consumers' behaviors at different time spans and reaching to more accurate results about online shopping continuation. Further, the model of this research can be tested in different regions and cultures to verify the distinct types of relationships existed in the model.

\section{Acknowledgements}

The authors are thankful to the Deanship of Scientific Research at King Saud University represented by the Research Centre in the College of Business Administration for financially supporting this research.

\section{References}

Afshan, S., \& Sharif, A. (2016a). Acceptance of mobile banking framework in Pakistan. Telematics and Informatics, 33(2), 370-387. http://doi.org/10.1016/j.tele.2015.09.005

Afshan, S., \& Sharif, A. (2016b). Telematics and Informatics Acceptance of mobile banking framework in Pakistan. Telematics and Informatics, 33(2), 370-387. http://doi.org/10.1016/j.tele.2015.09.005

Alshehri, M., \& Drew, S. (2012). The Effects of Website Quality on Adoption of E-Government Service: An Empirical Study Applying UTAUT Model Using SEM. 23rd Australian Conference On Information System, (2011), 1-13.

Anderson, J. C., \& Gerbing, D. (1988). Structural modeling in practice: A review and recommended two-steps approach. Psychological Bulletin, 103(3), 411-423.

Aren, S., Güzel, M., Kabadayı, E., \& Alpkan, L. (2013). Factors Affecting Repurchase Intention to Shop at the Same Website. Procedia Social and Behavioral Sciences, 99, 536-544. http://doi.org/10.1016/j.sbspro.2013.10.523

Baptista, G., \& Oliveira, T. (2015). Understanding mobile banking: The unified theory of acceptance and use of technology combined with cultural moderators. Computers in Human Behavior, 50, 418-430. http://doi.org/10.1016/j.chb.2015.04.024

Bhattacherjee, A. (2001). Understanding Information Systems Continuance: An Expectation-Confirmation Model Author(s Qarterjy 
UNDERSTANDING INFORMATION SYSTEMS CONTINUANCE: AN EXPECTATION- CONFIRMATION MODEL1 Motivation for the Study. Anol Bhattacherjee Source: MIS Quarterly, 25(3), 351-370.

Davis, F. D. (1989). Perceived Usefulness, Perceived Ease of Use, and User Acceptance of Information Technology. MIS Quarterly, 13(3), 319-340. http://doi.org/10.2307/249008

Dishaw, M. T., \& Strong, D. M. (1999). Extending the technology acceptance model with task-technology fit constructs. Information \& Management, 36(1), 9-21. http://doi.org/10.1016/S0378-7206(98)00101-3

Fornell, C., \& Larcker, D. F. (1981). Evaluating Structural Equation Models with Unobservable Variables and Measurement Error. Journal of Marketing Research (JMR). Feb1981, 18(1), 39-50. 12p. 1 Diagram. http://doi.org/10.2307/3151312

Gefen, D., Karahanna, E., \& Straub, D. W. (2003). Trust and TAM in Online Shopping: An Integrated Model. MIS Quarterly, 27(1), 5190. http://doi.org/10.1007/s13398-014-0173-7.2

Gefen, D., \& Straub, D. W. (2004). Consumer trust in B2C e-Commerce and the importance of social presence: Experiments in eProducts and e-Services. Omega, 32(6), 407-424. http://doi.org/10.1016/j.omega.2004.01.006

Goles, T., Lee, S., Rao, S. V., \& Warren, J. (2009). Trust violation in electronic commerce: customer concerns and reactions. Journal of Computer Information Systems, 49, 1-9.

Goodhue, D. L., \& Thompson, R. L. (1995). Task-Technology Fit and Individual Performance. MIS Quarterly, 19(2), $213-236$. http://doi.org/10.2307/249689

Hassanein, K., \& Head, M. (2007). Manipulating perceived social presence through the web interface and its impact on attitude towards online shopping. International Journal of Human Computer Studies, 65(8), 689-708. http://doi.org/10.1016/j.ijhcs.2006.11.018

Hoelter, J. W. (1983). The analysis of covariance structures: goodness-of-fit indices. Sociological Methods and Research, 11, 325-344. http://doi.org/10.1177/0049124183011003003

Hong, S., Thong, J. Y. L., \& Tam, K. Y. (2006). Understanding continued information technology usage behavior: A comparison of three models in the context of mobile internet. Decision Support Systems, 42(3), 1819-1834. http://doi.org/10.1016/j.dss.2006.03.009

Hung, S.-Y., Chang, C.-M., \& Kuo, S.-R. (2013). User acceptance of mobile e-government services: An empirical study. Government Information Quarterly, 30(1), 33-44. http://doi.org/10.1016/j.giq.2012.07.008

Internet World Stats. (2015). Retrieved from http://www.internetworldstats.com/middle.htm\#sa

Kim, G., Shin, B., \& Lee, H. G. (2009). Understanding dynamics between initial trust and usage intentions of mobile banking. Information Systems Journal, 19(3), 283-311.

Kim, K. K., \& Prabhakar, B. (2004). Initial trust and the adoption of B2C e-commerce: The case of internet banking. ACM Sigmis Database, 35(2), 50-64.

Kim, M. J., Chung, N., \& Lee, C. K. (2011). The effect of perceived trust on electronic commerce: Shopping online for tourism products and services in South Korea. Tourism Management, 32(2), 256-265. http://doi.org/10.1016/j.tourman.2010.01.011

Kim, S. S., \& Malhotra, N. K. (2005). A Longitudinal Model of Continued IS Use: An Integrative View of Four Mechanisms Underlying Postadoption Phenomena. Management Science, 51(5), 741-755. http://doi.org/10.1287/mnsc.1040.0326

Klopping, I. M., \& McKinney, E. (2004). Extending the technology acceptance model and the task-technology fit model to consumer ecommerce. Information Technology Learning and Performance Journal, 22, 35-48.

Lee, K. S., Lee, H. S., \& Kim, S. Y. (2007). Factors Influencing the Adoption Behavior of Mobile Banking: A South Korean perspective. Journal of Internet Banking \& Commerce, 12(2).

Lee, M. C. (2010). Explaining and predicting users' continuance intention toward e-learning: An extension of the expectation-confirmation model. Computers and Education, 54(2), 506-516. http://doi.org/10.1016/j.compedu.2009.09.002

Lee, Y., \& Kwon, O. (2011). Intimacy, familiarity and continuance intention: An extended expectation-confirmation model in web-based services. Electronic Commerce Research and Applications, 10(3), 342-357. http://doi.org/10.1016/j.elerap.2010.11.005

Makki, E., \& Chang, L. (2015). Understanding the Effects of Social Media and Mobile Usage on E-Commerce: An Exploratory Study in Saudi Arabia. International Management Review, 11(2), 98-110.

Malaquias, R. F., \& Hwang, Y. (2016). An empirical study on trust in mobile banking: A developing country perspective. Computers in Human Behavior, 54, 453-461.

Moon, J. W., \& Kim, Y. G. (2001). Extending the TAM for a World-Wide-Web context. Information and Management, 38(4), $217-230$. http://doi.org/10.1016/S0378-7206(00)00061-6

Oliveira, T., Faria, M., Thomas, M. A., \& Popovi??, A. (2014). Extending the understanding of mobile banking adoption: When UTAUT meets TTF and ITM. International Journal of Information Management, 34(5), 689-703. http://doi.org/10.1016/j.ijinfomgt.2014. 06.004

Shin, D. H. (2007). User acceptance of mobile Internet: Implication for convergence technologies. Interacting with Computers, 19(4), 472-483. http://doi.org/10.1016/j.intcom.2007.04.001

Thong, J. Y. L., Hong, S. J., \& Tam, K. Y. (2006). The effects of post-adoption beliefs on the expectation-confirmation model for information technology continuance. International Journal of Human Computer Studies, 64(9), 799-810. http://doi.org/10.1016/ j.ijhcs.2006.05.001

Venkatesh, N., \& Davis, F. D. (2000). A theoretical extension of the technology acceptance model: four longitudinal field studies. Management Science, 46(2), 186-204.

Wen, C., Prybutok, V., \& Xu, C. (2011). An integrated model for customer online repurchase intention. Journal of Computer Information Systems, (FEBRUARY), 14-23.

Yuan, S., Liu, Y., Yao, R., \& Liu, J. (2014). An investigation of users' continuance intention towards mobile banking in China. Information 
Development. http://doi.org/10.1177/0266666914522140

Zhou, T. (2012). Understanding users' initial trust in mobile banking: An elaboration likelihood perspective. Computers in Human Behavior, 28(4), 1518-1525.

Zhou, T., Lu, Y., \& Wang, B. (2010). Integrating TTF and UTAUT to explain mobile banking user adoption. Computers in Human Behavior, 26(4), 760-767. 